\title{
The Design and Implementation of the Attendance Management System based on Radio Frequency Identification Technology
}

\author{
Kong Shengli, Zhao Jun, Shi Guang, Wu Chunhong, \\ Zhao Wenpei \\ State Grid Henan Electric Power Research Institute \\ Zhengzhou, China
}

\author{
Liu Tao \\ State Grid Henan Electric Power Corporation Maintenance \\ Company \\ Zhengzhou, China
}

\begin{abstract}
Radio Frequency Identification(RFID) is a technology of non-contact automatic identification. By reading the information stored in the RFID tag, it can carry out the positioning, identification and tracking of objects. Now RFID is highly developed and has been widely used in business, transportation, logistics and other fields. With the rapid development of modern communication technology, attendance management can be more scientific and accurate. This paper researches on attendance system by using RFID, and a RFID card automatic attendance system is designed. In the realized system, Windows is the operating platform, Visual $\mathrm{C}++6$ is the development tool, and MYSQL is the database. The software system is connected to the database by ODBC, the Windows API function realizes the serial communication, and the Arduino microcontroller is connected with the RFID reader. Through the real-time database to record and save the attendance data information, this system can be widely used in the enterprise to manage the employee's attendance.
\end{abstract}

Keywords-RFID; Electronic tag; automatic attendance system

\section{INTRODUCTION}

RFID is a comprehensive technology which is based on the development of computer and communication, non-contact coupling of radio frequency signal through coupling element between the electronic tag and reader. Within the coupled channels and according to the temporal relations, it achieves energy transmission and data exchange. When the tag enters the magnetic field, the radio frequency signal can be received by the reader, the tag is powered by the energy of the induced current and sends out the product information stored in the chip(Passive Tag). Or the tag is initiative to send a signal frequency(Active Tag). After RFID device reads the information and decoding, it would be sent to the central information system on data processing. RFID system is different from magnetic card and IC card which are contact recognition technology, and RFID Information can be obtained without physical contact between the RFID card and reader, at the same time, RFID can realize multi-object recognition, moving object recognition, which can be applied in a wider range of occasions. Its main advantage is that the environment adaptability is strong and not affected by the weather, and it can penetrate non-metallic objects to identify, possess strong anti-interference ability. Therefore, it has attracted the attention of various countries and enterprises.

RFID is a new application domain, which not only covers the microwave technology and electromagnetic theory, but also includes the principle of communication and semiconductor integrated circuit technology, which is a multiinterdisciplinary area. Therefore, the understanding and research of RFID technology has a profound theoretical significance.

School attendance is an essential part of daily teaching[1]. In the past, the work of students' attendance is mainly borne by the teachers, which would take a few minutes before class or after class for calling class name. In this condition, it consumes the teaching time, also does not have the flexibility. From the record attendance data and analyze the attendance records, it is need to spend the extra time and effort[2]. In this paper, the computer technology and RFID technology are used in the attendance management system, which can effectively improve the efficiency of the attendance management and improve students' attendance rate, bring great convenience to the teachers and the educational administration department. Through the real-time database to record and save the attendance data information, this system can be widely used in the enterprise to manage the employee's attendance.

\section{RELATED WORKS}

At present, there are a lot of foreign schools have the application of RFID system in the management of the students[3-5].

In the Literature[6], the active RFID system is applied in the students monitoring system, which includes two tasks: attendance record and tracking. The system uses RFID technology to monitor the whereabouts of a specific student, which improve the management of the attendance data and improve the management efficiency of the teachers. In the literature[7], a student database management system based on RFID was designed, and the system attaches the RFID tag to the student's ID card, which provides data about all the 
students, including the basic information of the student which includes such as attendance, course, etc. At the same time, it can be used to track the students' attendance. RFID and fingerprint identification system are applied to the management of students and equipment in boarding school in literature[8], when students wear a RFID card, the monitoring system based on RFID identity information and fingerprint detection to confirm the identity of students, so as to record the students' whereabouts and enhance the safety of the equipment.

Many aboard schools apply a kind of intelligent monitoring attendance[9, 10], both in primary school and middle school and RFID technology is used for each student to apply for electronic student card, to automatic manage the students' attendance, and their leaving time. A lot of university students apply for a card which is based on RFID technology, and one card can handle all kinds of things in the campus, such as card spending, enter the department and so on. The system is not only for students' learning and life to provide a convenient method, but also to strengthen the school's security management.

\section{DEMAND ANALYSIS}

The attendance management system based on RFID technology is gather information through the acquisition of read/write device, and the records are stored in the database. Students usually need to carry out a RFID card to sign. For a formal system, we need to make sure that only a certain competence of personnel can login system. Therefore, the attendance system adopts the safety measures of different grades. Because the system function is more specific, so the demand analysis are also relatively concentrated, and the following requirements of the system are derived:

(1)Information management for students;

(2)Acquisition of student attendance record;

(3)Deal with the attendance records, statistics, etc;

(4)Maintenance of database;

(5)Different user login for different user rights.

Specific analysis is as follows:

(1)Source analysis:

According to the needs of attendance management system, the system information source is consist of student information, RFID card information and attendance record. RFID card information includes card distribution information, report the loss of information, activation information. The attendance record information includes RFID card attendance and student attendance record.

(2)System user analysis

The user of this system can be divided into three aspects: the administrator, leaders and students. The administrator could use the operation of information management, set up time, query the operation and the database management. Leadership can investigate student attendance, who have the right to register their students with a radio frequency card. In addition, leadership also have the right to query information, modify the user password, etc.. Students only have the right to query and modify the password. Each user's operation of the authority is subject to certain restrictions, which can protect the security of information system.

(3)The information integrity and security analysis

For the system information security considerations, and in order to prevent the system from power leakage and information by unauthorized tampering, each type of user has their own user name and password with the correct permissions to login the system. In order to prevent the users of the system changes when the query system information, the safety of the system mainly takes the following two measures: 1)To provide the user with the appropriate authority, they can only operate the data within their authority.

2)Establish an independent transfer mechanism in the admin layer, set up a redundant database for backup check. At the same time, the redundant database is the foundation of the restore database system. On the integrity of the information, it must meet the entity integrity and referential integrity requirements. According to the actual need to define some special constraints, that is the user defined integrity. These requirements jointly guarantee the integrity of the system.

\section{SOFTWARE AND HARDWARE SELECTION}

The acquisition of the RFID card information is carried out under the MFC $\mathrm{VC}++6.0$ windows and interface design in MFC. The database was carried out in Sever MySQL 5.1, Navicat is used for MySQL database to build the table view interface, test and query operations. The realization of the hardware is RC522 MF reader module(as shown in Fig.1) and RFID tag (as shown in Fig.2).

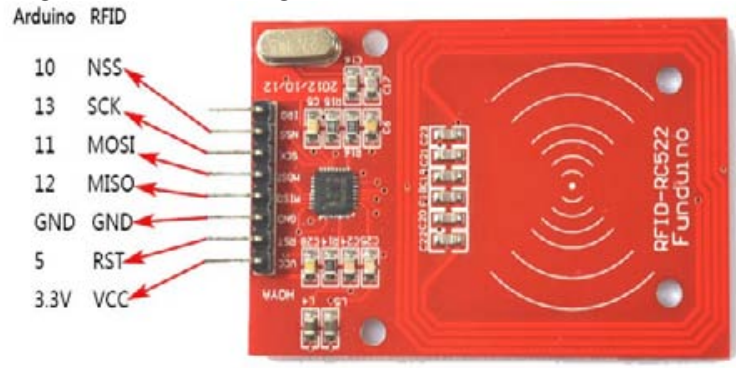

Figure 1. RC522 RFID reader

The student ID card uses passive RFID tags, when it is in the effective area of the reader to send information to the reader, so that the reader can read the RFID information. Each student card stores the student number ID.

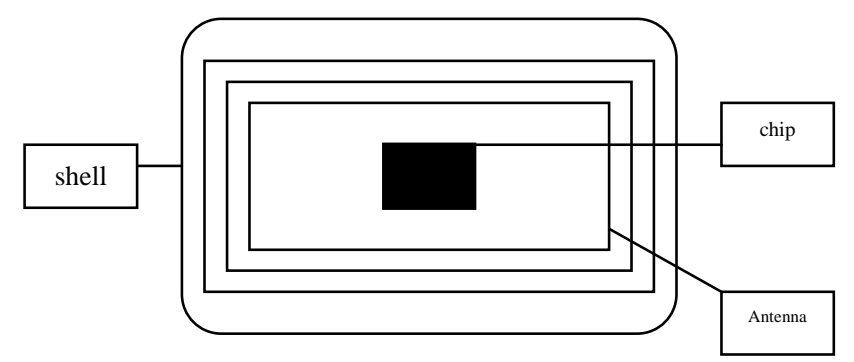

Figure 2. RFID tag 
Arduino is an open source controller board, which adopt a soft hardware platform based on open source code. In this paper, the RC522 RFID reader is connected to the Arduino platform for the acquisition of RFID card information (as shown in Fig.3).

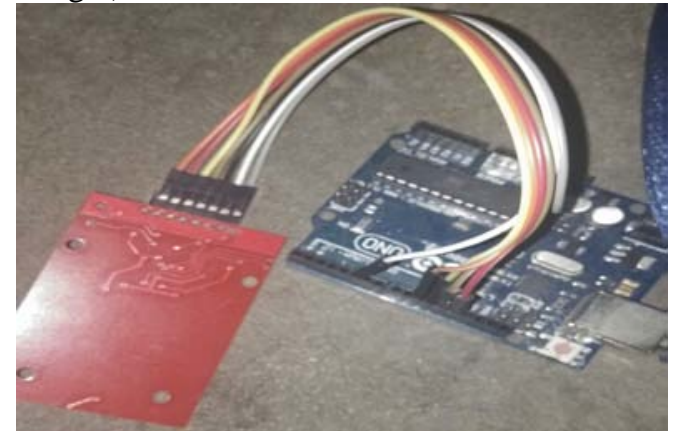

Figure 3. Arduino and RC522 Reader connection

\section{Design of AtTendance System}

When students go through the door of the classroom, the RFID card reader machine can automatically sense attendance, and the system record the attendance time through the teaching building door without waiting. Then, the reader need to upload information to computer terminal for processing accurate record of the student's arriving time and other information. The system frame is shown in Fig. 4 and Fig. 5.

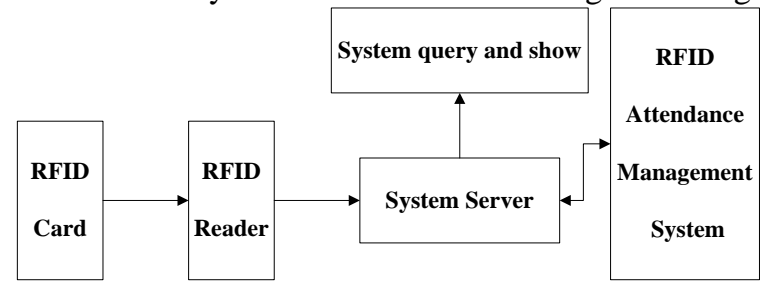

Figure 4. Attendance system structure

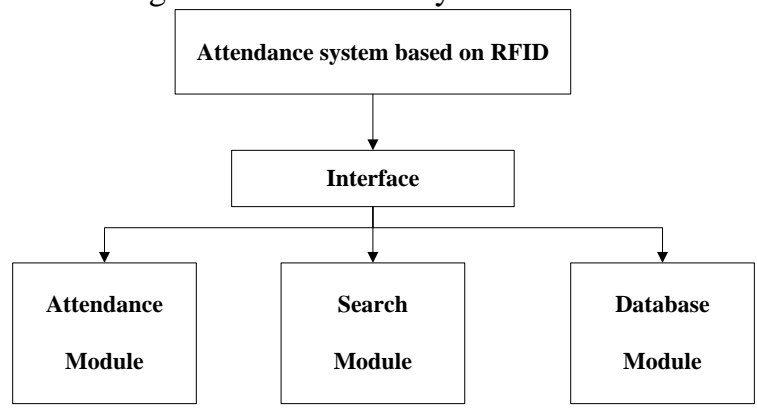

Figure 5. Attendance system module

\section{CASE DESCRIPTION}

\section{A. Execute solution}

$13.56 \mathrm{MHz}$ radio frequency identification are used for students attendance management. All people wear a passive electronic tag as a time record card. As long as the tag is in the active recognition range of the reader, it can automatically recognize the tag information, and record attendance information by the software system.
Attendance data is mainly composed of attendance table which includes: Student attendance sheet (student card ID, student ID, course name, attendance time). Considering the number of students is overmuch, query operation will take up a lot of database server resources, so take class as a unit, each class of student attendance results with a table to save, which would reduce the burden on the database server.

The work process is the following steps:

(1)Get the student card information;

(2)Generate attendance record;

(3)Save attendance results. It is shown in Fig.6.

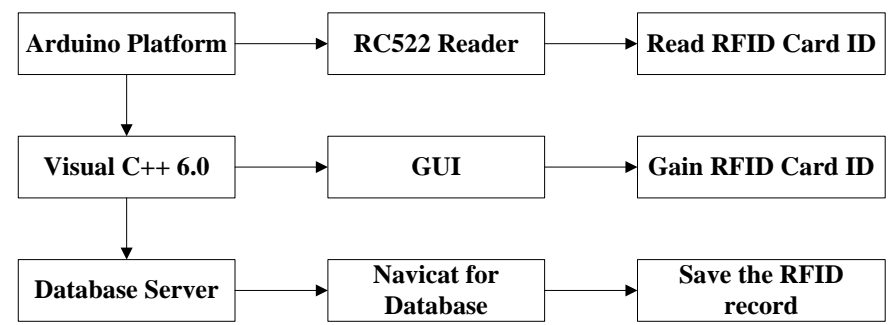

Figure 6. the work flow chart of the attendance recording

\section{B. System core function}

1)Accurate identification card information, and the correct record attendance time;

2)By reader the card, the computer record everyone's attendance record in detail;

3)The attendance information is saved to the database in order to query, which is shown in table I.

TABLE I. DATABASE TABLE

\begin{tabular}{|c|c|c|c|}
\hline Name & $\begin{array}{c}\text { Field } \\
\text { names }\end{array}$ & Data type & Primary key \\
\hline Card number & _id & int & YES \\
\hline $\begin{array}{c}\text { Student } \\
\text { number }\end{array}$ & _stuNum & varchar & NO \\
\hline Class & _course & varchar & NO \\
\hline $\begin{array}{c}\text { Attendance } \\
\text { time }\end{array}$ & _time & time & NO \\
\hline
\end{tabular}

The advantages of this attendance system based on RFID has the following two advantages:

(1)Simplify the process, improve the efficiency of attendance

The existing attendance system requires students to close their card reader to record attendance information, such operation process would be more complicated. The student attendance system based on RFID can avoid those problems, students just put the card in specific places so that the reader could receive the attendance information, which would greatly improved the speed and efficiency of check on attendance.

(2)Improve the correct rate of attendance 
Traditional attendance tends to be crowded or busy, which may have a large number of students to carry out the work, sometimes a few card together to read operation, leakage may occur, so that the attendance becomes inaccurate. But the RFID just solve this problem, it can read the card at a long distance, so the misreading or missing is avoided, which would be more efficiency and easy for attendance record.

The difference of RFID technology-based attendance and traditional technology's attendance are shown in table II.

TABLE II. THE DIFFERENCE BETWEEN RFID TECHNOLOGY AND TRADITIONAL TECHNOLOGY OF CHECK ON WORK ATTENDANCE.

\begin{tabular}{|c|c|c|}
\hline Function & Traditional technology & RFID technology \\
\hline Operate convenience & Internal staff slot card and record & $\begin{array}{c}\text { Automatic identification of internal staff } \\
\text { attendance management into the database. } \\
\text { External visitors through the RFID card } \\
\text { automatic identification of personnel } \\
\text { information }\end{array}$ \\
\hline Field operation & Registration time is long and prone to error & $\begin{array}{l}\text { All equipment identification without human } \\
\text { interference }\end{array}$ \\
\hline Alternative & $\begin{array}{l}\text { Paper attendance card and documentation are not } \\
\text { eco_friendly }\end{array}$ & recycling \\
\hline Identity information & Artificial judgment & Tag judgment \\
\hline Operation flow & Punch or manual registration mode & No need to contact, automatic identification \\
\hline $\begin{array}{l}\text { Resources, data } \\
\text { accuracy }\end{array}$ & low & high \\
\hline Advanced management & $\begin{array}{c}\text { Traditional manual management, special personnel } \\
\text { statistics }\end{array}$ & $\begin{array}{l}\text { The system automatically generates the } \\
\text { attendance report }\end{array}$ \\
\hline Working status & No & Buzzer and indicator \\
\hline
\end{tabular}

\section{CONCLUSION}

This paper is aimed at the automatic attendance management, which takes student attendance as example, designation of attendance management system based on RFID technology. The whole system is based on RFID card which is the information identification, achieve attendance related data storage, processing, statistics, and taking into account information security. The permissions are set up to meet the actual needs of different users. On the other hand, the system can also be installed on campus, teachers and counselors on the computer terminal system which can be aware of the distribution of students in the campus. In addition, the system can also be used as a smart teacher conference report system, improve the efficiency of meeting management work. With the rapid development of RFID technology, the system will be improved and widely used in enterprise staff's attendance management.

\section{References}

[1] K. Singh, A. Sharma, G. Rajput, and D. Kasturia, "RFID Attendance System Project," International Journal of Research, vol. 1, no. 11, pp. 347349, 2014.
[2] M. Zhi and M. M. Singh, "RFID-Enabled Smart Attendance Management System," in Future Information Technology-II: Springer, 2015, pp. 213-231.

[3] M. Kassim, H. Mazlan, N. Zaini, and M. K. Salleh, "Web-based student attendance system using RFID technology," in Control and System Graduate Research Colloquium (ICSGRC), IEEE, 2012, pp. 213-218.

[4] A. S. Tiwari, A. S. Tiwari, N. M. Ade, S. G. Sheikh, N. R. Patel, and A. R. Khan, "Optimized Design of Student Attendance System Using RFID," in International Conference on Machine Learning, Electrical and Mechanical Engineering, 2014, pp. 8-9.

[5] O. T. Arulogun, A. Olatunbosun, O. A. Fakolujo, and O. M. Olaniyi, "RFID-based students attendance management system," International Journal of Scientific \& Engineering Research, vol. 4, no. 2, pp.1-9, 2013.

[6] F. M. Al-Naima and M. A. Saleh, "A Proposed RFID Based Student Attendance System," Int. J. Com. Net. Tech, vol. 3, no. 2, pp. 49-58, 2015.

[7] K. Hu and L. Li, "Mining a New Movement Pattern in RFID Database on Internet of Things," International Journal of Database Theory and Application, vol. 7, no. 2, pp. 37-44, 2014.

[8] R. Mehta, N. Bhattacharya and S. Goyal, "RFID and ASP. NET based Campus Management System," International Journal of Computer Applications, vol. 88, no. 4, pp. 29-32, 2014.

[9] M. A. Abas, T. B. Tuck and M. Dahlui, "Attendance Management System (AMS) with fast track analysis," in International Conference on, Computer, Control, Informatics and Its Applications (IC3INA), 2014, pp. 3540.

[10] S. Tucker, P. Darcy and B. Stantic, "A comparative study of RFID technology measuring efficiency and acceptance when capturing attendance," in Proceedings of the Thirty-Seventh Australasian Computer Science Conference-Volume 147, 2014, pp. 75-79. 